\title{
Experimental Study on Corrosion of Anchored Rock Mass for Half-Through Intermittent Joints
}

\author{
Wantao Ding $\left(\mathbb{D},{ }^{1,2}\right.$ Mingjiang Li, ${ }^{2}$ Mingbin Wang, ${ }^{3}$ Rui Chen, ${ }^{2}$ Yang Wang, ${ }^{2}$ and Lei Chen ${ }^{2}$ \\ ${ }^{1}$ Research Center of Geotechnical and Structural Engineering, Shandong University, Jinan 250061, China \\ ${ }^{2}$ School of Qilu Transportation, Shandong University, Jinan 250002, China \\ ${ }^{3}$ School of Civil Engineering, Ludong University, Yantai 264025, China \\ Correspondence should be addressed to Wantao Ding; dingwantao@sdu.edu.cn
}

Received 18 January 2019; Revised 15 April 2019; Accepted 5 May 2019; Published 28 May 2019

Academic Editor: Claudio Mazzotti

Copyright (C) 2019 Wantao Ding et al. This is an open access article distributed under the Creative Commons Attribution License, which permits unrestricted use, distribution, and reproduction in any medium, provided the original work is properly cited.

\begin{abstract}
Make crackled mortar test block to simulate jointed rock mass reinforced by anchor bars. Computational model of corrosion penetration at different load times can be obtained by corrosion acceleration through electrochemistry. Through observation of anchor bar after corrosion, it is found that primary corrosion is mainly pitting; however, with the development of corrosion, corrosion moves along etch pit to the upper and lower surfaces so as to form partial corrosion. Meanwhile, computational formula of pitting ratio is put forward on the basis of mass loss rate. It is found that, through the pulling out experiment of anchor bar corrosion, corrosion has remarkable influence on anchoring performance of anchor bar; meanwhile, different pitting ratios have different influences on trends of ultimate bond strength, for example, when pitting ratio is bigger (between 9\% and 30\%), the biggest decreasing rate of bond strength is obviously lower than that under lower pitting ratio (from 1.5\% to 5\%). According to linear fitting of experimental data, the relationship curve of $K$, ultimate bond strength ratio, and pitting ratio can be obtained so as to provide basis for judgement of anchoring performance loss in practical engineering.
\end{abstract}

\section{Introduction}

As a key part of underground engineering structure, anchorage structure has become the preferred method for underground engineering reinforcement due to its low cost, fast construction, and small occupied space. As the most frequently used supporting structures, anchor bars can effectively control the deformation failure of rock mass in practical engineering. However, anchor bars usually work in poor geological conditions with more corrosive media. Especially in the construction of subsea tunnels, chloridion in seawater is easy to penetrate and erode due to the multijointed fractured rock mass in the crossing area, resulting in serious corrosion of anchor bars and damage of anchorage structures, which threaten the security of tunnels operation and cause great potential safety hazards.

In recent years, many scholars have done a lot of experimental research and theoretical analysis on the bonding properties of corroded steel bars and achieved a lot of achievement [1-7]. Apostolopoulos and Papadakis carried out accelerated corrosion tests on steel bars, and the corrosion results were in good agreement with the corrosion performance of steel bars in practical engineering [8]. By describing the assessment of a reinforced concrete canal structure of power plant after 20 years of exposure in a marine environment, Bayuaji et al. predicted no strength reduction due to corrosion by 2025 [9]. Four degradation models of bond stress between steel bar and concrete with different diameters were studied by experiments. The coupling effect of bond between concrete and corroded steel bar was determined by $\mathrm{Wu}$ et al. Based on various factors, a simplified calculation model of bond strength between cracked concrete and severely corroded deformed steel bar is established [10]. Cabrera and Auyeung studied the effect of corrosion rate on the characteristics of rust expansion cracking and bond strength through accelerated corrosion 
test by electrification and established the corresponding relationship expression [2, 11]. Law and Molyneaux carried out an experimental study on the change of bond strength of reinforced concrete specimens before cracking and explored the influence of reinforcement diameter, protective layer thickness, and other factors on bond strength [12].

Referring to the relevant research results of corroded steel bars, the corrosive research of anchor bars has also been carried out and some achievements have been achieved [13-17]. Ding and Li, based on FLAC ${ }^{3 \mathrm{D}}$ anchorage model and strength reduction idea of finite element method, analyzed the deterioration effect of reinforcement rust on the bonding force between anchor bar and grouting body and the strength of anchor bar [18]. Wu et al. designed and built a loading frame capable of withstanding tensile stress. The stress corrosion cracking of full-scale anchor bars (up to $2.4 \mathrm{~m}$ in length) was studied by simulating field conditions [19]. Xu et al. draws lessons from the research results of corrosion of reinforced concrete structures and considers the influence of surrounding rock and initial in-situ stress on the underground anchorage environment, respectively. The cracking process of mortar protective layer caused by corrosion of anchor bars is analyzed [20]. Hassell evaluated the corrosion rate of a series of rock anchor structures through long-term underground environment simulation tests and in-situ test results. Based on this, the service life of the anchor structures is estimated, and the effect of corrosion on the bearing capacity and reinforcement performance of rock anchor structures is revealed [21]. Through indoor model test, Wen et al. discussed the anchoring mechanism of anchor cable anchoring rock mass with joint surface and analyzed the influence of installation inclination of anchor cable and roughness of joint surface on shear strength [22]. Through theoretical analysis, Li et al. studied the constitutive model and fracture mechanism of discontinuous jointed rock mass, established the fracture damage constitutive model of rock mass with anchored joints, and established the damage evolution equation of cracks under compressionshear and tension-shear conditions [23].

In conclusion, there is some progress in the research on the degradation of bond properties caused by steel bar corrosion, but there are few studies on the corrosion damage of intermittent joints and anchored rock mass, and most of the existing studies are based on the analysis of uniform corrosion. This is not always conformed with the real case. In addition, there are also few studies on the corrosion pattern of steel bar in jointed fractured rock mass and the migration law of corroded materials in joints. Considering that the quantitative analysis of rock mass anchored corrosion migration will have a great influence on the mechanical analysis of anchored structure, this paper obtains the calculation model of corrosion rate and corrosion time through indoor corrosion test of intermittent anchored joint specimens. Based on pitting corrosion, the concept of pitting corrosion rate is put forward, and the regular pattern of rust migration with pitting corrosion rate is analyzed. The relationship curve between the ultimate bond strength coefficient and pitting corrosion rate is fitted, and the variation law of anchoring performance and pitting corrosion rate of jointed rock mass is determined. It has important guiding significance for analyzing the safety and durability of anchoring structure in jointed rock mass tunnel.

\section{Experimental Design}

2.1. Preparation and Corroding of Specimens with Anchored Jointed Rock Mass. Considering the special working condition that the anchor bar and the joint are in contact with each other in the reinforcement of discontinuous jointed rock mass, a semipenetrating jointed rock mass specimen with $75 \mathrm{~mm} \times 75 \mathrm{~mm} \times 150 \mathrm{~mm}$ rectangular mortar is prepared. A HRB335 screw bar with a diameter of $8 \mathrm{~mm}$ is built into the center. The quality ratio of the mortar is shown in Table 1. The cement is Portland cement grade 42.5 ordinary Portland cement produced by Sunnsy Group. The sand is produced in Jiyang, Jinan Province. Four kinds of sand with different particle sizes were used. The proportion was 10 meshes to 20 meshes, 20 meshes to 40 meshes, 40 meshes to 70 meshes, 70 meshes to 120 meshes which was $1.247: 6.25$ : $3.11: 1.57$. Water used was pure water. The water-reducer is UNF-3A retarding efficient pumping agent. When cement mortar is poured, fissures are simulated by embedded thin iron sheets. The inclination angles of prefabricated fissures are $30^{\circ}$ and $45^{\circ}$. The corresponding sizes of fissures are $53 \times 37.5 \times 1 \mathrm{~mm}$ and $75 \times 37.5 \times 1 \mathrm{~mm}$, respectively. The length of built-in steel bar is $170 \mathrm{~mm}$, in which the length of anchorage section is $120 \mathrm{~mm}$, the bare length of steel bar is $50 \mathrm{~mm}$, and the thickness of the bottom mortar protective layer is $30 \mathrm{~mm}$. The complete specimen and its size are shown in Figure 1. After the specimens were poured, the specimens were cured in standard curing room for 7 days, and the measured cubic compressive strength of concrete for 7 days was $60 \mathrm{MPa}$.

In the natural environment, the corrosion of anchor bars is a very long process. In the existing studies, most of them are about natural condition corrosion in 10, 20, or even longer years. In order to shorten the test cycle and speed up the process of test and research, the test scheme of accelerating rust has been adopted by more and more researchers. There are two existing methods: artificial natural accelerated corrosion and electrical accelerated corrosion. The former is more similar to natural corrosion, and the simulation is more practical. However, the time required is longer than the latter, and the corrosion degree cannot be quantitatively controlled during the corrosion process. The latter takes less time, and based on Faraday's law, the corrosion degree of anchor bars can be preliminarily determined. However, there are some differences between the simulation and the actual corrosion mechanism, and there are some deviations between the simulation and the actual situation. In this experiment, the method of accelerating rust by electrification is adopted, and the three-electrode electrolytic system is adopted based on the test instrument used. Three-electrode system refers to a system consisting of working electrodes, reference electrodes, and auxiliary electrodes. Three electrodes consist of two circuits, one for measuring potential and the other for measuring current. A circuit consisting of a working electrode and a reference electrode is used to 
TABLE 1: Mix proportion of mortar quality.

\begin{tabular}{lcccccc}
\hline \multirow{2}{*}{ Cement $(\mathrm{g})$} & \multicolumn{2}{c}{ Dinas $(\mathrm{g})$} & & \multirow{2}{*}{ Water $(\mathrm{g})$} & Water-reducer $(\mathrm{g})$ \\
& $10 \sim 20$ meshes & $20 \sim 40$ meshes & $40 \sim 70$ meshes & $70 \sim 120$ meshes & 157 & 350 \\
\hline 1000 & 1247 & 625 & 311 & 157 & 20 \\
\hline
\end{tabular}

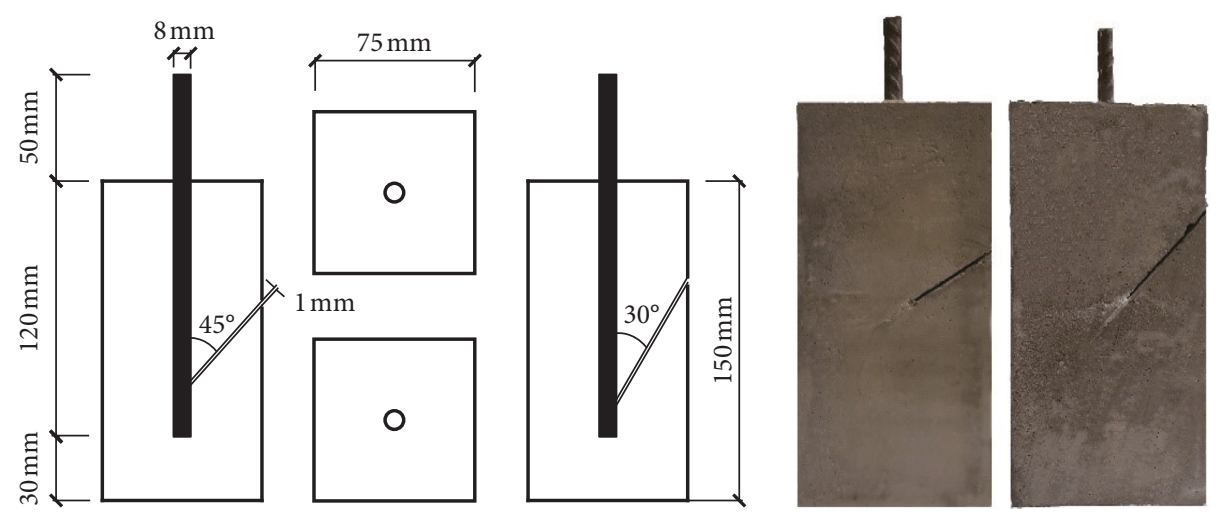

FIgURE 1: Complete specimen and its dimension drawing.

measure the potential of the electrode because the potential of the reference electrode is known. Working electrodes and auxiliary electrodes form another circuit to measure current. In this way, a "three-electrode two-loop" system is formed, which is commonly used as a three-electrode system.

The instrument used in the test is VersaSTAT electrochemical workstation with high accuracy. The threeelectrode system can better ensure the constant current in the process of accelerating corrosion, effectively reduce the error caused by current fluctuation in the test process, and make the test results more accurate. The accelerating corrosion device is shown in Figure 2. The corrosive environment is natural seawater environment. The test block is immersed in seawater. The bare anchor bar is connected to the working electrode, the carbon rod is connected to the auxiliary electrode, and the silver chloride electrode is connected to the reference electrode. The constant current and the required loading time are set by matching software. Seawater is added in time during loading to ensure the constant volume of seawater. In order to determine the ion content in seawater, we tested it. The results are shown in Table 2.

In order to obtain the calculation model of the amount of rust with time, the error between the amount of rust calculated by Faraday's law and the actual amount of rust was corrected, and the calibration test design was carried out. The current is constant, and the current density is $3.18 \mathrm{~A} / \mathrm{m}^{2}$ during the accelerated corrosion process. And the loading time is 12 hours as a time interval. Eight groups of tests were carried out for 24 hours, 36 hours, 48 hours, 60 hours, 72 hours, 84 hours, 96 hours, and 108 hours for two kinds of specimens from different angles.

The measurement and calculation of corrosion amount are carried out according to the following procedure. When making specimens, the reinforced bar with length of $17 \mathrm{~cm}$ is intercepted. According to the requirements of Text code for hydraulic concrete (SL 352-2006), the anchor bar is acid

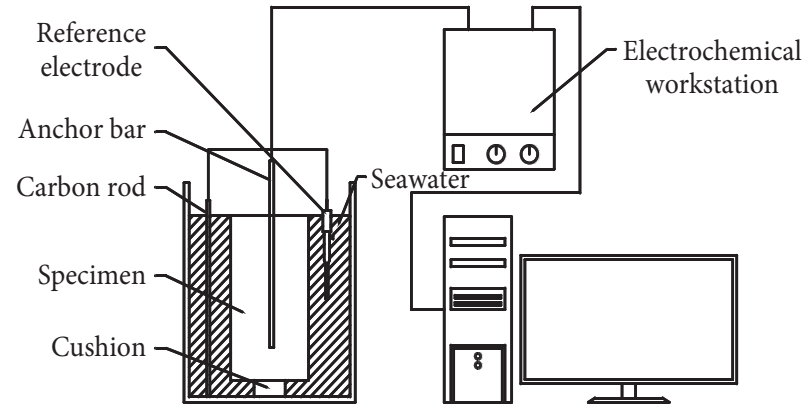

FIGURE 2: Schematic diagram of electrochemical accelerated corrosion device.

TABle 2: Testing table for seawater composition used in the experiment.

\begin{tabular}{lc}
\hline Ion & Concentration $(\mathrm{mg} / \mathrm{L})$ \\
\hline Calcium ion $\left(\mathrm{Ca}^{2+}\right)$ & 431 \\
Magnesium ion $\left(\mathrm{Mg}^{2+}\right)$ & 1348 \\
Sodium ion $\left(\mathrm{Na}^{+}\right)$ & 11458 \\
Potassium ion $\left(\mathrm{K}^{+}\right)$ & 421 \\
Chloride ion $\left(\mathrm{Cl}^{-}\right)$ & 36530 \\
Sulfate ion $\left(\mathrm{SO}_{4}^{2-}\right)$ & 2539 \\
Bicarbonate ion $\left(\mathrm{HCO}_{3}^{-}\right)$ & 160 \\
Nitrate ion $\left(\mathrm{NO}_{3}^{-}\right)$ & 4 \\
\hline
\end{tabular}

washed. The acid pickling solution is hydrochloric acid solution (industrial hydrochloric acid: water $1: 1$, plus $2 \%$ $3 \%$ hexamethylenetetramine of pure hydrochloric acid mass), and the neutralizing solution is $3 \%$ sodium carbonate solution. The anchor bar is soaked in the pickling solution and removed after the surface oxide scale is dissolved. Then take out the anchor bar and rinse it with water, then dry it with a dry towel, and bake it in the oven for 5 minutes, until the pickling is finished. After acid pickling, the reinforcing 
bar was numbered and weighed, and the initial weight of reinforcing bar was recorded (accurate to $0.001 \mathrm{~g}$ ), which is expressed as $m_{0}$. After the accelerated corrosion is completed, the specimens are broken and the corroded anchor bars are taken out. The corroded anchor bars are also pickled and removed in accordance with the requirements of Text code for hydraulic concrete (SL 352-2006). After pickling, the anchor bars are weighed and recorded according to the existing number. The quality of the corroded anchor bars is expressed in $m$. The initial mass minus the mass of the corrosion is the mass loss of the corrosion, which is expressed in $m_{1}$. The calculation formula is shown in equation (1). The rate of mass loss is the ratio of mass loss to the original quality of reinforcing bar. The calculation formula is shown in equation (2).

$$
\begin{gathered}
m_{1}=m_{0}-m, \\
\gamma=\frac{m_{1}}{m_{0}} .
\end{gathered}
$$

2.2. Experimental Design of Anchorage Performance. At present, there are four testing methods for anchorage performance: central pull-out test, central tension test, beam test, and column test. The central pull-out test is also one of the methods adopted by most researchers. The instrument used in the experiment is WDW-IOOE III universal testing machine. Because bare anchor bars exist at only one end of the specimen, the fixture of the testing machine cannot clamp the other end of the specimen, so the reaction frame is needed in the experiment. The reaction frame is shown in Figure 3, and the connection of pull-out test specimens is shown in Figure 4. In the process of drawing, the control program of universal tester automatically records the drawing force and displacement curve in the test.

\section{Analysis of Test Results}

3.1. Analysis of Corrosion Quantity Calculation Model. According to Faraday's law, the theoretical model for calculating the amount of rust is shown in equations (3) and (4):

$$
\begin{aligned}
M & =K Q=K i t, \\
K & =\frac{M_{\mathrm{mo}}}{F n} .
\end{aligned}
$$

In equations (3) and (4), $M$ is the mass of the precipitated metal, $K$ is the proportional constant (electrochemical equivalent), $Q$ is the passing electric quantity, $i$ is the current intensity, $t$ is the electrifying time, $M_{\mathrm{mo}}$ is the molar mass of the substance, $F$ is the Faraday constant (the value is $9.65 \times 10000 \mathrm{C} / \mathrm{mol}$ ), and $n$ is the absolute value of the total positive or negative valence in the compound.

According to the measurement and calculation method in Section 2.1, the corrosion amount is measured. The measurement results are shown in Table 3.

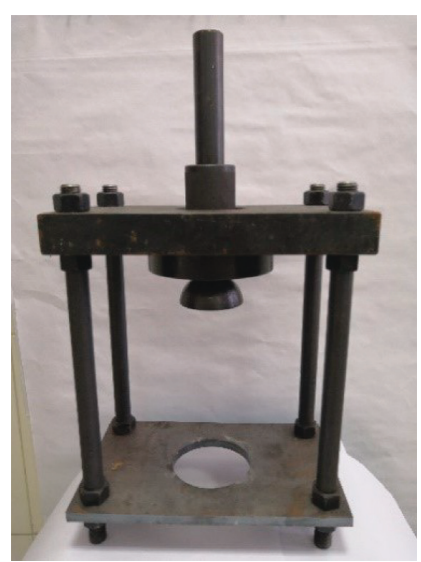

FIgURE 3: Space drawing instrument.

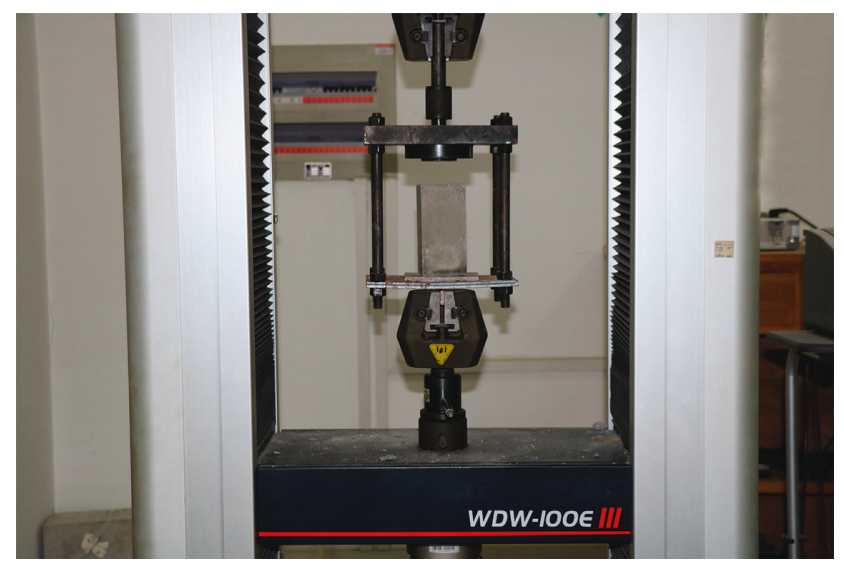

FIGURE 4: Connection diagram of specimens.

By substituting the constant current into the formula, the theoretical corrosion quantity relationship can be obtained as follows: $M=1.044 \times 10^{-3} \mathrm{t}$. The actual corrosion quantity data are fitted, and the fitting curve can be obtained as follows: $30^{\circ}$ fracture angle specimen: $M=1.044 \times 10^{-3} \mathrm{t}$ and $45^{\circ}$ fracture angle specimen: $M=1.044 \times 10^{-3}$ t. The comparison of the two curves is shown in Figure 5.

Figure 5 shows that the actual amount of corrosion is larger than that calculated by theory. Analyzing the shape of anchor bar after corrosion, it can be seen that because of the existence of joint cracks, the anchor bar at the joint cracks contacts with seawater directly and corrodes, so the contact point is where the corrosion occurs first and mainly, and the development of corrosion is based on the corrosion that occurs here. By observing the corroded anchor bars, it is found that pitting corrosion mainly occurs, as shown in Figure 6. The shape of pitting corrosion is mainly groove. The existence of joint cracks makes the rust products spill over continuously. Then the contact area between seawater and anchor bars becomes larger and larger, which makes the corrosion rate increase continuously.

Artificial cracks with 30 degree and 45 degree angles were selected in specimen fabrication. However, according to the test results, there is not much difference in the amount 
TABLE 3: Test quality record.

\begin{tabular}{lcccccc}
\hline $\begin{array}{l}\text { Loading } \\
\text { time }\end{array}$ & $\begin{array}{c}\text { Theoretical } \\
\text { corrosion }\end{array}$ & $\begin{array}{c}\text { Initial mass } \\
(\mathrm{g})\end{array}$ & $\begin{array}{c}30^{\circ} \text { angle specimen } \\
\text { Quality after corrosion } \\
(\mathrm{g})\end{array}$ & $\begin{array}{c}\text { Mass loss } \\
(\mathrm{g})\end{array}$ & $\begin{array}{c}\text { Initial mass } \\
(\mathrm{g})\end{array}$ & $\begin{array}{c}45^{\circ} \text { angle specimen } \\
\text { Quality after corrosion } \\
(\mathrm{g})\end{array}$ \\
\hline 24 & 0.0251 & 42.947 & 42.906 & 0.041 & 43.666 & 43.620 \\
36 & 0.0376 & 43.237 & 43.181 & 0.056 & 42.946 & 42.892 \\
48 & 0.0501 & 43.577 & 43.497 & 0.08 & 43.128 & 43.045 \\
60 & 0.0626 & 43.483 & 43.387 & 0.096 & 43.331 & 0.046 \\
72 & 0.0752 & 42.913 & 42.804 & 0.109 & 43.508 & 43.237 \\
84 & 0.0877 & 43.437 & 43.320 & 0.117 & 42.255 & 43.405 \\
96 & 0.1002 & 43.317 & 43.175 & 0.142 & 42.528 & 42.130 \\
108 & 0.1128 & 43.283 & 43.283 & 0.171 & 44.404 & 42.392 \\
\hline
\end{tabular}

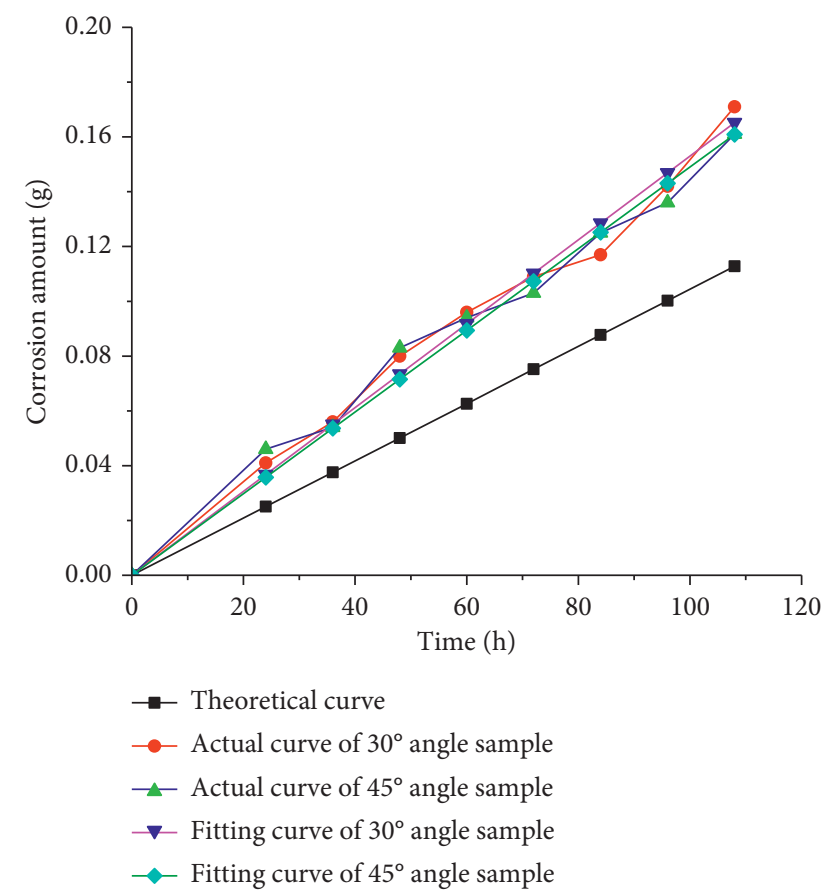

Figure 5: Contrast diagram of fitting curves of $30^{\circ}$ and $45^{\circ}$ fracture angle.

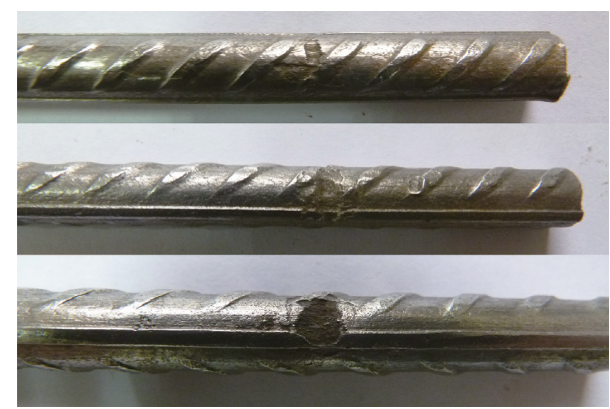

FIGURE 6: The picture of pitting shape.

of actual corrosion products between specimens with different angles under the same other conditions. Under the same current density of $3.18 \mathrm{~A} / \mathrm{m}^{2}$, under the same load for 24 hours, the actual corrosion mass of the specimens with $30^{\circ}$ angle is $0.041 \mathrm{~g}$ and that of the specimens with $45^{\circ}$ angle is $0.046 \mathrm{~g}$. The difference between the two is not large. The other test results can refer to the test data in Table 3. Therefore, according to the test results, it shows that the angle of joints and cracks has no significant effect on the amount of corrosion. In addition, the actual corresponding relationship between other factors affecting rust, such as current and chloride ion concentration, and the amount of rust, has not been validated due to the time relationship and will be further validated in subsequent experiments.

3.2. Corrosion Morphology Analysis of Anchor Bar. Because the reinforcing bar in the mortar test block is in a high-alkaline environment, a layer of "passivating film" is formed, which makes the anchor bar not easy to rust. But once the passivating film is destroyed, the anchor bar will be rusted quickly. The chloride ion is a very strong deactivator. The content of chloride in seawater used in this test reaches $36.53 \mathrm{~g} / \mathrm{L}$. Even in the environment with high alkalinity, it can destroy the passivating film of anchor bars and make the corrosion process proceed. The contact between anchor bars and seawater at cracks is more direct, so under the action of electrochemical workstation, corrosion rapidly occurs and expands, forming larger pits. With the prolongation of corrosion time, most of the corrosion products will flow out of the cracks. In addition, the corrosion will move slowly along the pit upwards and downwards to corrode the surface of the anchor bar, which will reduce the bonding performance of the anchor bar itself and greatly reduce the overall anchoring performance.

Since pitting corrosion is the main corrosion, the corresponding relationship between the corrosion mass and the current is determined by the analysis of calibration test. It is inaccurate to calculate the corrosion rate according to the overall mass loss of the anchorage section, because the longer the length of the anchorage section, the smaller the corrosion rate under the same amount of corrosion, which can not accurately reflect the corrosion situation. Therefore, the concept of pitting ratio is proposed. The pitting ratio is calculated using

$$
\delta=\frac{m_{\mathrm{e}}}{m_{\mathrm{c}}}
$$

In equation (5), $\delta$ is the pitting corrosion rate, $m_{\mathrm{e}}$ is the mass of overflow rust products (the calculation formula and measurement method are shown in Section 3.3), and $m_{\mathrm{c}}$ is 
the original mass of anchor bars at pits. The calculation is done using

$$
m_{\mathrm{c}}=\rho \pi r^{2} b .
$$

In equation (6), $m_{c}$ is the original mass of the anchor bar at the corrosion pit, $\rho$ is the density of the anchor bar, $r$ is the radius of the anchor bar, and $b$ is the width of the corrosion pit along the length direction of the reinforcement bar, which can be obtained by actual measurement.

3.3. Rust Migration Analysis. After breaking the test block and removing the anchor bars, it was found that the surface of the anchor bars above and below the corrosion pit was corroded, but the degree of corrosion was different. After removing the anchor bars, the quality of the overflow corrosion products was obtained by weighing them directly:

$$
m_{\mathrm{e}}=m_{0}-m^{\prime} \text {. }
$$

In equation (7), $m_{\mathrm{e}}$ is the quality of overflow corrosion products, $m^{\prime}$ is the quality of anchor bar before pickling, and $m_{0}$ is the quality of anchor bar before corrosion. The mass ratio of spilled rust products to total rust products is obtained by comparing the quality of spilled rust products with that of total rust products:

$$
C_{\mathrm{e}}=\frac{m_{0}-m^{\prime}}{m_{0}-m} .
$$

In equation (8), $C_{\mathrm{e}}$ is the percentage of the total quantity of corrosion products, and $m$ is the quality of anchor after pickling.

The variation of spillage quality and percentage of mass with pitting ratio is shown in Figure 7.

Figure 7 shows that, with the increase of rust amount, the quality of spilled rust products increases, and the mass percentage of spilled rust products increases. When the pitting ratio is $1.83 \%$, the quality of overflow corrosion product is $0.012 \mathrm{~g}$ and the mass ratio is $16.17 \%$. When pitting corrosion rate reached $27.54 \%$, the quality of overflow corrosion product is $0.378 \mathrm{~g}$, increased by 30.5 times, and the mass proportion was $40.46 \%$, increased by 1.5 times. It can be seen that the quality of overflow corrosion product increased much faster than its mass proportion. By observing the corrosion of anchor bars after corrosion, the overflow corrosion products mainly come from the corrosion at the pit, while the corrosion products attached to the anchor bars mainly come from the corrosion on the surface of anchor bars above and below the pit. It shows that, with the increase of the corrosion rate, the corrosion rate at the pit slows down, while the corrosion on the surface of the anchor bars above and below the pit is serious. That is to say, with the increase of corrosion rate, the corrosion of anchor bars is not simply pitting corrosion but gradually developed into local corrosion which has been pitting corrosion.

With the increase of corrosion rate, local corrosion aggravates and different areas of rust migration along the pit upward and downward are observed. Since it is impossible to accurately measure the amount of rust products migrating in

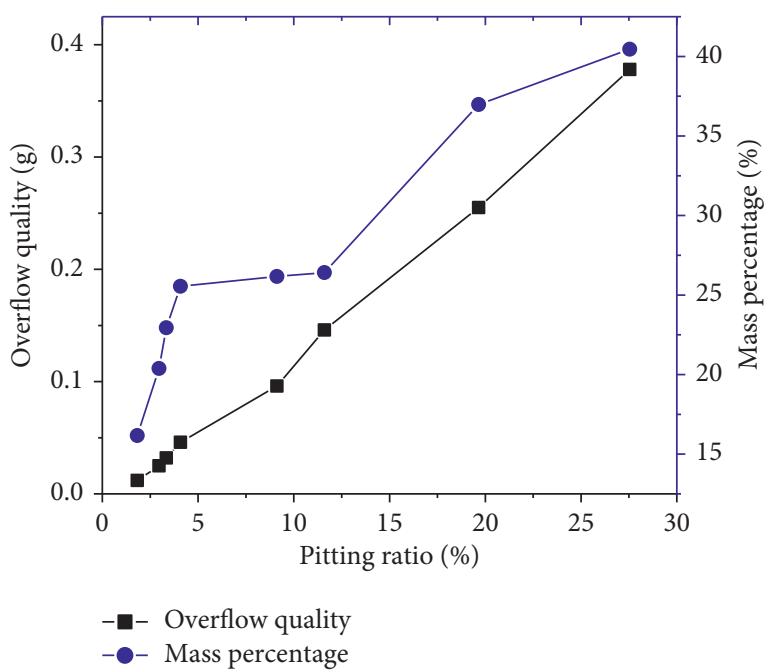

FIgURE 7: Variation diagram of spillage quality and mass percent change with pitting corrosion rate.

different directions, the degree of rust is analyzed by observing and measuring the minimum and maximum distance and average distance of rust migration in different directions.

Figures $8-10$ show migration distances in different directions. From Figures $8-10$, it can be seen that the migration distances in different directions increase with the pitting corrosion rate increasing, which indicates that the area of corrosion has been increasing, and the distance of upward migration is larger than that of downward migration. In terms of average migration distance, the upward migration distance is about 1.3 times that of the downward migration distance, which means that the corrosion develops more seriously upward along the pit and the area of corrosion above the pit is larger. Before the pitting corrosion rate reaches $5 \%$, the migration distance increases rapidly and the corrosion develops rapidly. The reason is that the crevice between anchor bar and mortar increases due to the formation of corrosion pits, and chloride ions rapidly invade along the crevice in two directions, which leads to the acceleration of corrosion on the surface of anchor bar. Later, with the increase of corrosion rate, the migration distance increases slowly and then slows down slowly. The reason is that the chloride ion penetration rate slows down with the distance from the crack and the failure rate of passive film of anchor bar slows down, so the corrosion rate of anchor bar slows down. Moreover, the local corrosion of anchor bar occurs on the side of the corrosion pit, and the corrosion pit is relatively uniform. Corrosion on the opposite side of the pit is lighter and basically noncorrosive.

Based on the average distance curve of migration in two directions, the exponential function is fitted. In this way, the rule of the migration distance varying with pitting corrosion rate can be obtained. Based on this, the migration distance can be roughly judged according to pitting corrosion rate. As shown in equations (9) and (10).

Upward migration:

$$
l_{\mathrm{s}}=14.86-18.10 e^{-40.068}\left(R^{2}=0.955\right) .
$$




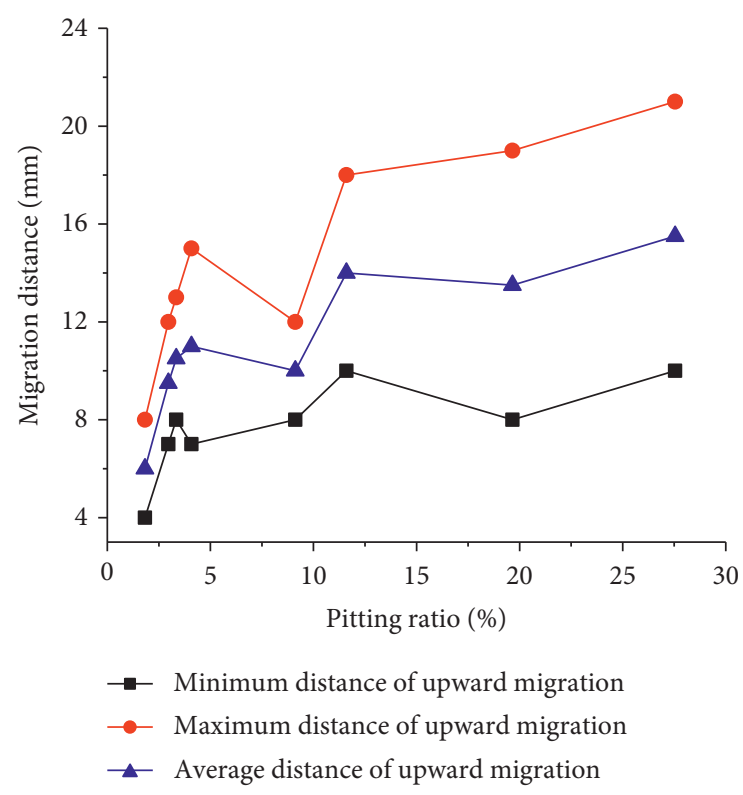

Figure 8: Diagram of upward migration pattern.

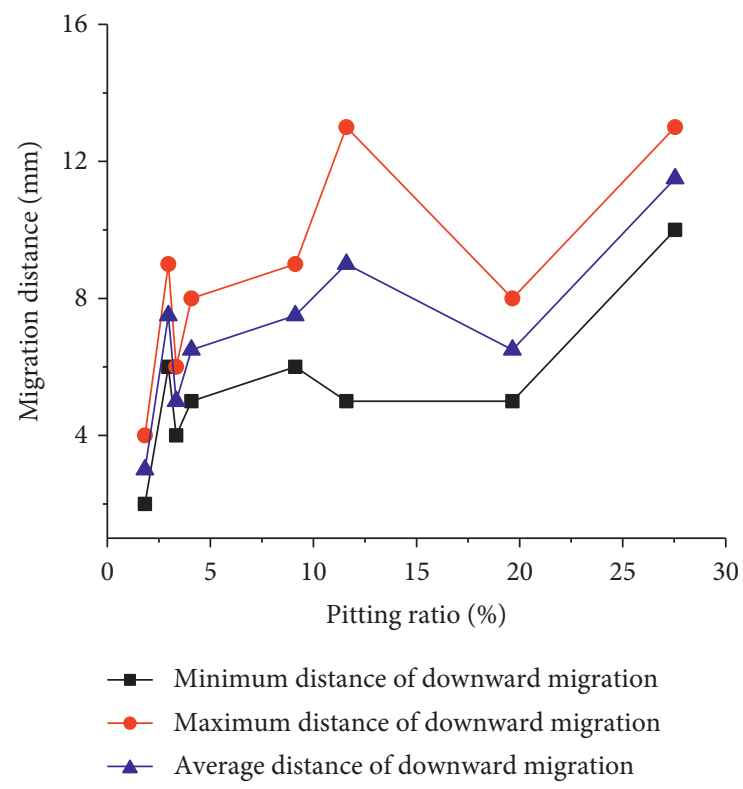

FIgURE 9: Diagram of downward migration pattern.

Downward migration:

$$
l_{\mathrm{x}}=11.86-10.04 e^{-10.90 \delta}\left(R^{2}=0.979\right) \text {. }
$$

3.4. Analysis of Anchorage Performance Test Results. Assuming that the bond stress is uniformly distributed along the anchorage length, the average bond stress is the ratio of the pull-out load to the surface area of the anchor bar on the anchorage section. The anchor bars at the cracks are exposed to seawater, so the area should be subtracted. The area diagram minus the area is shown in Figure 11, and the bond stress can be calculated as follows equation (11):

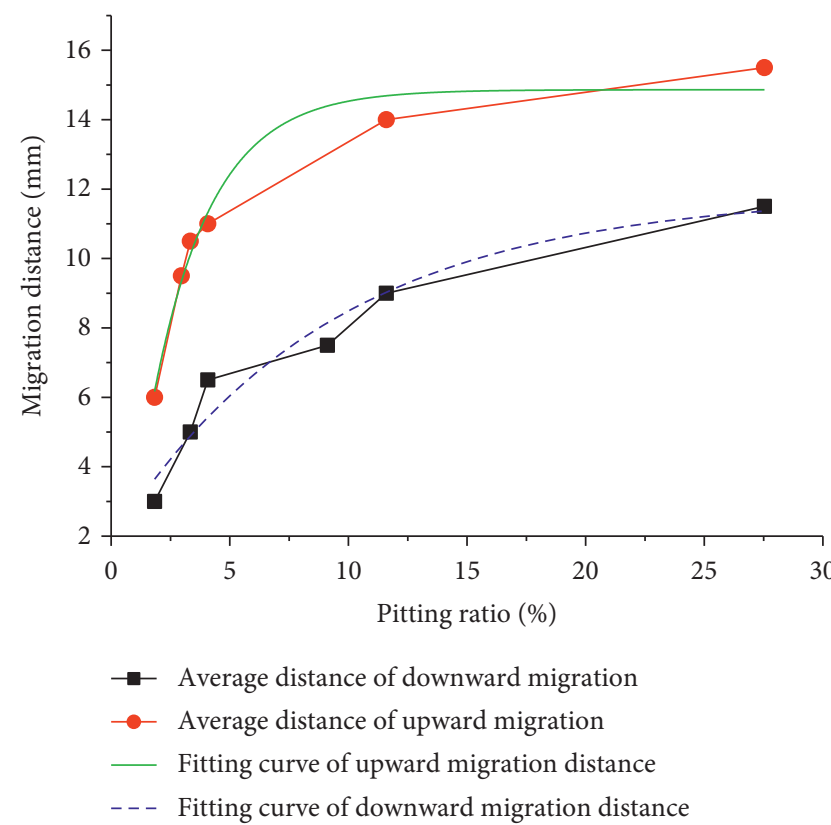

Figure 10: Migration distance contrast diagram in different direction.

$$
\tau=\frac{P}{\pi d l_{\mathrm{a}}-(1 / 2) \pi d l_{0}} .
$$

In equation (11), $P$ is the pull-out load, $d$ is the diameter of the anchor bar, $l_{\mathrm{a}}$ is the anchorage length, and $l_{0}$ is the length of the bare anchor bar, $l_{0}=h / \sin \theta$ ( $h$ is the crack width, $\theta$ is the inclination angle).

In the pull-out test, the slip reading $S_{\mathrm{L} 0}$ recorded by the universal testing machine loading program is the sum of the slip of the anchor bar relative to the specimen and the tensile deformation of the anchor bar, so it is necessary to determine the tensile deformation of the anchor bar. According to Hooke's law, the tensile deformation of anchor bar is as follows equation (12):

$$
\Delta S=\frac{F}{E A} L_{\mathrm{AB}} .
$$

In equation (12), $L_{\mathrm{AB}}$ is the original length of the anchor bar, $A$ is the theoretical area of the section of the anchor bar, $E$ is the elastic modulus of the anchor bar, and $F$ is the maximum pull-out load loaded on the anchor bar by the universal testing machine. So the actual slip $S_{\mathrm{L}}$ of bare anchor bars at the bearing end of mortar specimens is calculated as

$$
S_{\mathrm{L}}=S_{\mathrm{L} 0}-\Delta S
$$

The specific test sequence and corresponding experimental results are shown in Table 4 .

The displacement control is adopted in the pull-out test. With the increase of displacement and pull-out force, the anchor tendons begin to slip slowly and cracks first appear at the top of the specimen and then crack and peel off. Then the free end slip of the anchor bar accelerates, and the pull-out force quickly reaches its peak value and begins to decline. 


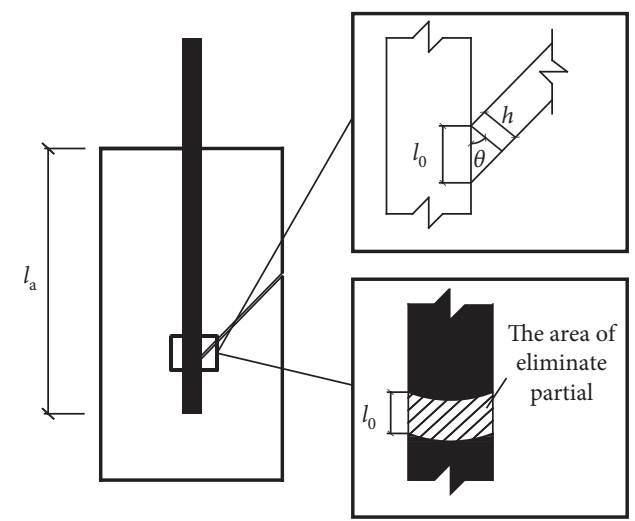

FIGURE 11: Schematic diagram of calculating area.

TABLE 4: Test sequence and test results.

\begin{tabular}{|c|c|c|c|c|c|c|c|}
\hline Sequence number & $\begin{array}{l}\text { Fracture } \\
\text { angle }\left({ }^{\circ}\right)\end{array}$ & $\begin{array}{c}\text { Current, } \\
I \\
(\mathrm{~mA})\end{array}$ & $\begin{array}{l}\text { Time, } \\
t(\mathrm{~h})\end{array}$ & Pitting ratio, $\delta(\%)$ & $\begin{array}{l}\text { Maximum drawing } \\
\text { force, } F(\mathrm{kN})\end{array}$ & $\begin{array}{l}\text { Bond strength, } \\
\tau(\mathrm{MPa})\end{array}$ & $\begin{array}{c}\text { Bond strength loss } \\
\text { rate }(\%)\end{array}$ \\
\hline A-30 & 30 & - & - & 0 & 20.42 & 6.83 & 0.00 \\
\hline A-30-1-48 & 30 & 1 & 48 & 1.83 & 18.94 & 6.33 & 7.24 \\
\hline A-30-1-72 & 30 & 1 & 72 & 2.96 & 18.61 & 6.22 & 8.86 \\
\hline A-30-1-96 & 30 & 1 & 96 & 3.34 & 18.34 & 6.13 & 10.19 \\
\hline A- $30-1-120$ & 30 & 1 & 120 & 4.08 & 17.76 & 5.94 & 13.00 \\
\hline B-45 & 45 & - & - & 0 & 20.96 & 6.99 & 0.00 \\
\hline B-45-1-48 & 45 & 1 & 48 & 1.72 & 18.76 & 6.26 & 10.50 \\
\hline B- $45-1-72$ & 45 & 1 & 72 & 2.79 & 18.49 & 6.17 & 11.80 \\
\hline B-45-1-96 & 45 & 1 & 96 & 6.29 & 17.91 & 5.98 & 14.53 \\
\hline B-45-1-120 & 45 & 1 & 120 & 4.67 & 17.70 & 5.90 & 15.54 \\
\hline C-30 & 30 & - & - & 0 & 21.50 & 7.19 & 0.00 \\
\hline C-30-5-48 & 30 & 5 & 48 & 9.12 & 15.40 & 5.15 & 28.40 \\
\hline C-30-5-72 & 30 & 5 & 72 & 11.60 & 13.90 & 4.65 & 35.34 \\
\hline C-30-5-96 & 30 & 5 & 96 & 19.65 & 12.85 & 4.30 & 40.25 \\
\hline C-30-5-120 & 30 & 5 & 120 & 27.54 & 11.58 & 3.87 & 46.14 \\
\hline $\mathrm{D}-45$ & 45 & - & - & 0 & 19.66 & 6.56 & 0.00 \\
\hline D-45-5-48 & 45 & 5 & 48 & 8.83 & 15.71 & 5.24 & 20.09 \\
\hline D- $45-5-72$ & 45 & 5 & 72 & 15.16 & 14.08 & 4.70 & 28.37 \\
\hline D-45-5-96 & 45 & 5 & 96 & 20.93 & 12.67 & 4.22 & 35.58 \\
\hline D-45-5-120 & 45 & 5 & 120 & 39.51 & 11.40 & 3.80 & 42.02 \\
\hline
\end{tabular}

Taking A-30-1-48 as an example, A represents different grouping, 30 represents crack angle of $30^{\circ}, 1$ represents loading current of $1 \mathrm{~mA}, 48$ represents loading time of 48 hours. One corrosion-free sample was used as control in each group.

After the anchor bar slip reaches a thread spacing, the pullout force loses almost.

Existing studies [10, 24-27] show that the volume expansion of rust products at the initial stage of corrosion results in rust expansion force, but the cracking of concrete has not yet occurred, which makes the ultimate bonding force increase slightly at first, and then decrease gradually with the deepening of corrosion. Due to the existence of joint cracks and the overflow of rust products, no corrosion expansion force is produced in this test, so the ultimate bonding force decreases directly with the increase of corrosion degree.

As shown in the bond strength-slip curve of the anchor bars in Figure 12, there is no relative slip between the anchor bars and the mortar body at the initial stage of loading when the load is small. At this time, the main bonding effect is the chemical bonding force between anchor bars and mortar. Later, the relative slip occurs when the load increases and exceeds a certain value. At this time, the main bonding force is the friction force and mechanical occlusion force between anchor bar and mortar body. After that, with the load increasing, cracks appear at the top of the specimen and the anchor bar bond, followed by cracking and spalling. The load reaches its maximum and decreases rapidly, and the slip increases rapidly. When the slip increases to a certain extent, the load stability will not change, and the friction between the two is the main bonding force.

In addition, it can be seen that the maximum bond strength of the specimens without corrosion corresponds to the slip displacement $S_{\mathrm{u}}$ of about $1.5 \mathrm{~mm}$ from the bond strength-slip curve of Figure 12. Then $S_{\mathrm{u}}$ decreases with the increase of corrosion degree of anchor bars. Taking group A 


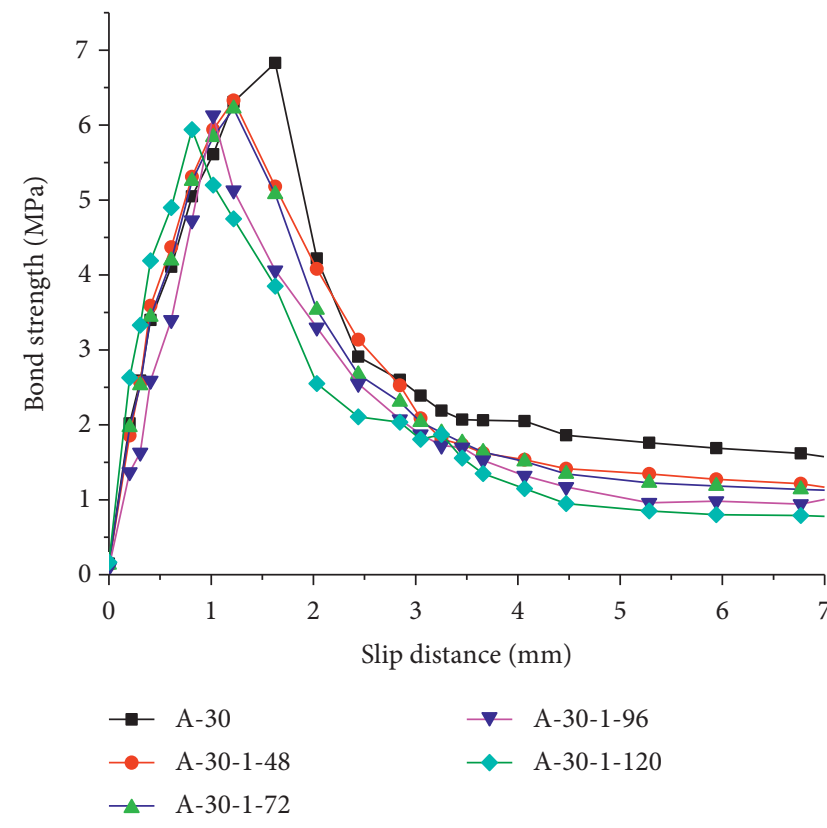

(a)

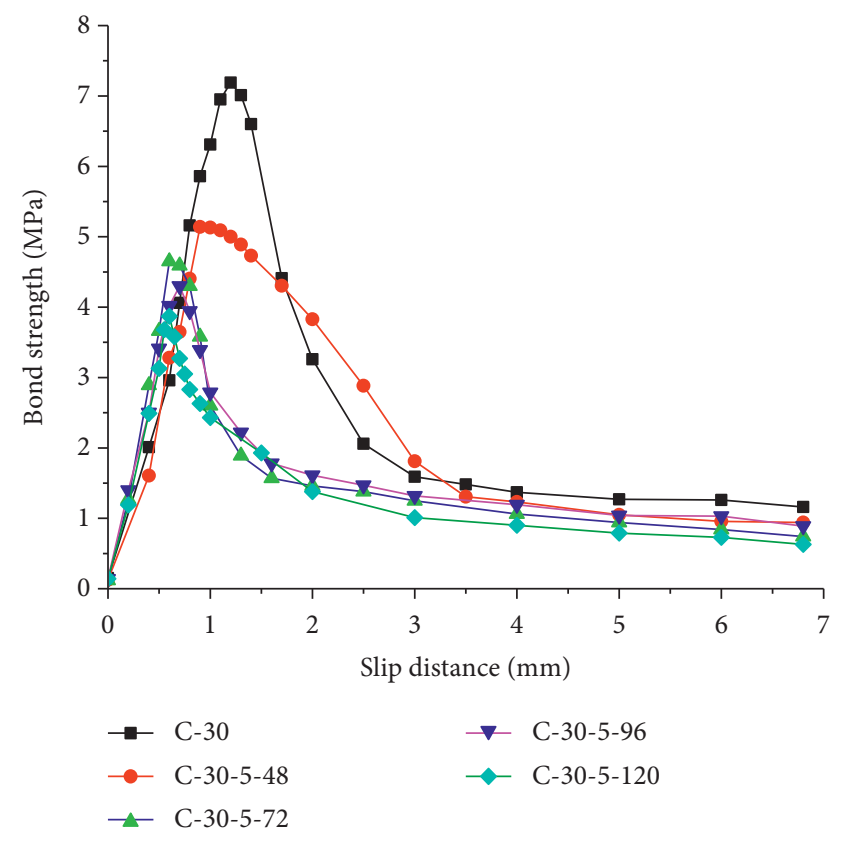

(c)

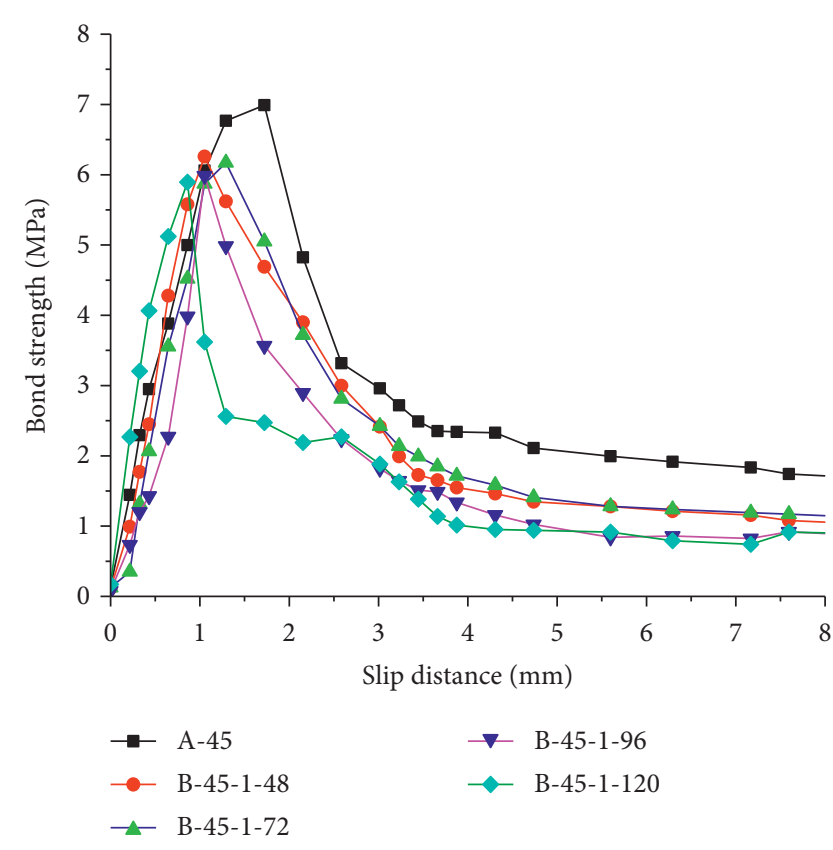

(b)

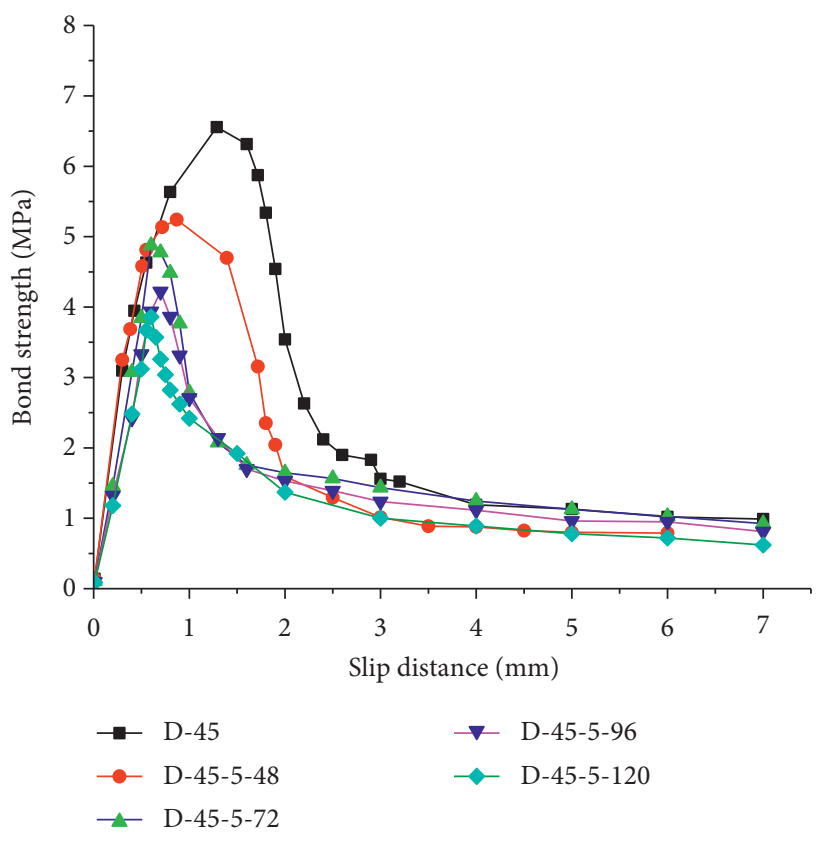

(d)

Figure 12: Bond strength-slip distance curve.

as an example, the corresponding slip value $S_{\mathrm{u}}$ of $1.83 \%$ pitting corrosion ratio specimens is about $1.2 \mathrm{~mm}$, the corresponding slip value $S_{\mathrm{u}}$ of $2.96 \%$ pitting corrosion ratio specimens is reduced to $0.95 \mathrm{~mm}$, the corresponding slip value $S_{\mathrm{u}}$ of $3.34 \%$ pitting corrosion ratio specimens is about $0.65 \mathrm{~mm}$, and the corresponding slip value $S_{\mathrm{u}}$ of $4.08 \%$ pitting corrosion ratio specimens is reduced to $0.55 \mathrm{~mm}$. At the same time, it can be seen that, with the increase of corrosion degree, the rate of $S_{\mathrm{u}}$ reduction is getting smaller and smaller.
In addition, the maximum bond strength and the pitting ratio curve of the four sets of specimens were linearly fitted, as shown in Figure 13. The regression equations of each group are shown in equations (14)-(17).

A group of regression equation:

$$
\tau=-20.77 \delta+6.80\left(R^{2}=0.976\right) .
$$

B group of regression equation:

$$
\tau=-15.23 \delta+6.73\left(R^{2}=0.751\right) .
$$




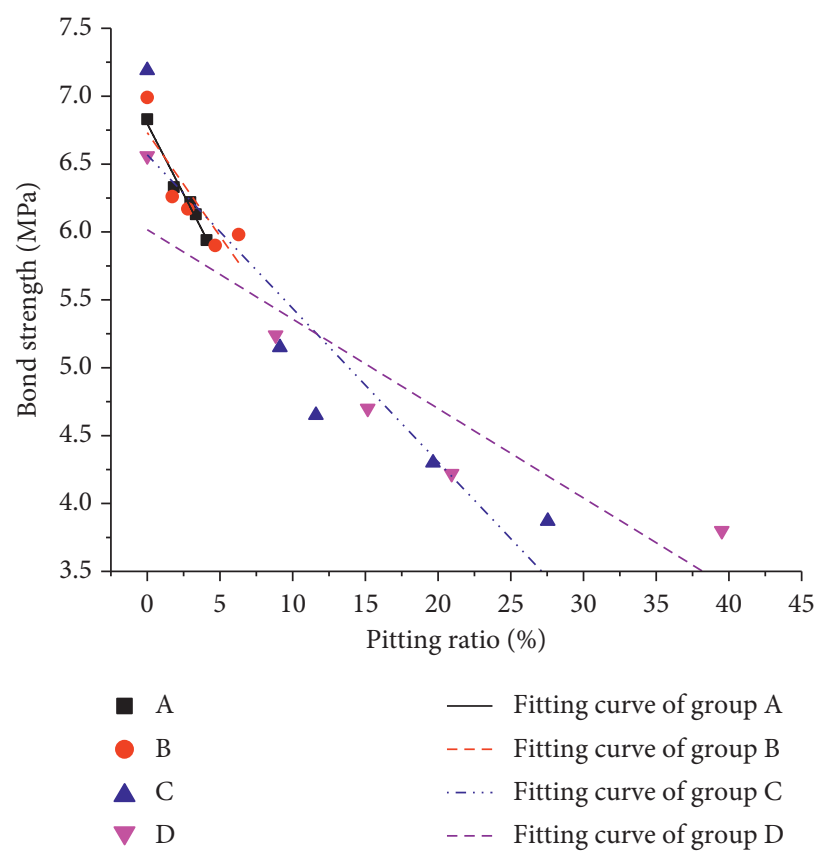

FIGURE 13: The linear fitting curve of the pitting corrosion ratio and the maximum bond curve.

C group of regression equation:

$$
\tau=-11.31 \delta+6.57\left(R^{2}=0.839\right)
$$

D group of regression equation:

$$
\tau=-6.59 \delta+6.02\left(R^{2}=0.835\right) .
$$

Comparing the slopes of the four curves, it can be found that the decrease rate of maximum bond strength at higher pitting corrosion ratio $(9 \%-30 \%)$ is lower than that of the maximum bond strength at smaller pitting corrosion ratio $(1.5 \%-5 \%)$.

After corrosion, the corrosion products on the surface of anchor bars cause the loss of bonding force on the surface of anchor bars, which results in the above phenomena. When the corrosion degree is low, the surface area of anchor bars adhering to corrosion products increases obviously. With the increase of corrosion degree, the surface of anchor bars at joints and cracks is completely covered by corrosion products, and corrosion pits begin to appear. At this time, the damage rate of bonding force basically reaches the maximum value. "Therefore, both the rate of slip reduction and the rate of maximum bond strength reduction will decrease significantly."

In addition, comparing the research on the constitutive relationship of bond-slip model of reinforced concrete after anchor corrosion by scholars at home and abroad, it is found that the ultimate bond strength coefficient of specimens increases gradually with the increase of corrosion rate when the corrosion rate of anchor bar is small. It can be inferred that the existence of joint cracks will aggravate the effect of corrosion on bond strength. This is mainly due to the existence of joints and cracks, which can cause corrosion products to escape from the bond of reinforced concrete. With the rust products escaping, the rust expansion force caused by rust will be greatly reduced, and even there will be voids in the bond of reinforced concrete in the corroded area, and the bond strength will be completely lost.

The ratio of the ultimate bond strength under different pitting ratio to the ultimate bond strength without corrosion is taken as the ultimate bond strength coefficient $K$. By fitting all the specimens, the relationship curves between the ultimate bond strength coefficient $K$ and pitting corrosion ratio at different fracture angles are obtained. The equations of the curves shown in Figure 14 are given in equations (18) and (19).

$30^{\circ}$ fracture angle:

$$
K=\frac{\tau}{\tau_{0}}=0.45 \delta^{-0.19}\left(R^{2}=0.960\right) .
$$

$45^{\circ}$ fracture angle:

$$
K=\frac{\tau}{\tau_{0}}=0.56 \delta^{-0.12}\left(R^{2}=0.871\right) .
$$

\section{Conclusion}

Considering the special working condition that the anchor bar and the joint of discontinuous jointed rock mass are in contact with each other, a mortar test block is made to simulate jointed rock mass. The corroded specimens were obtained by three-electrode galvanostatic method. Then the corresponding calibration and drawing tests were carried out on the specimens. Through the analysis of the experimental data, the following conclusions can be drawn.

(1) The amount of corrosion obtained by actual measurement is larger than that calculated by Faraday's law. Faraday's law is the relationship between the quantity of electricity passing through the electrode 


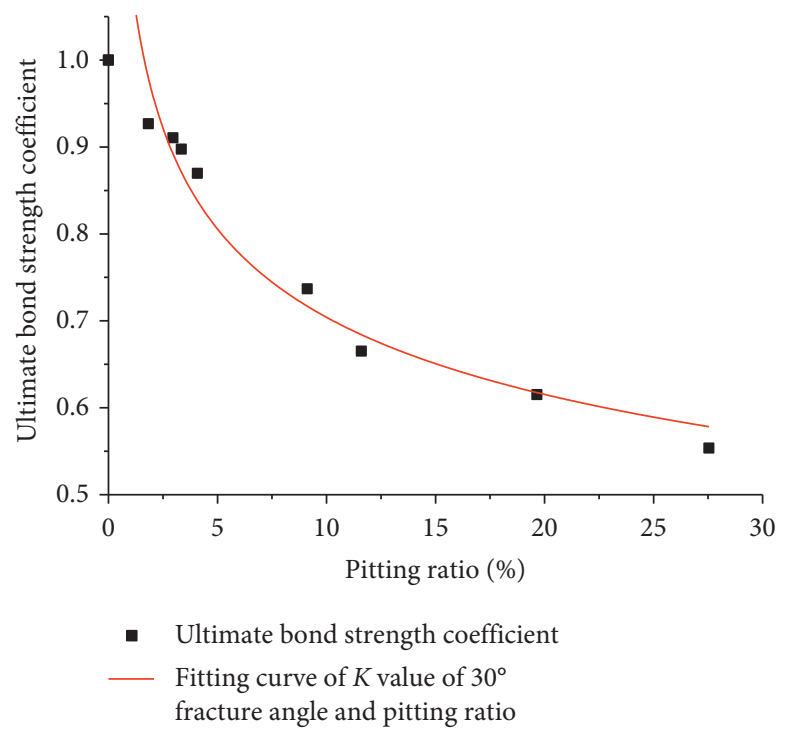

(a)

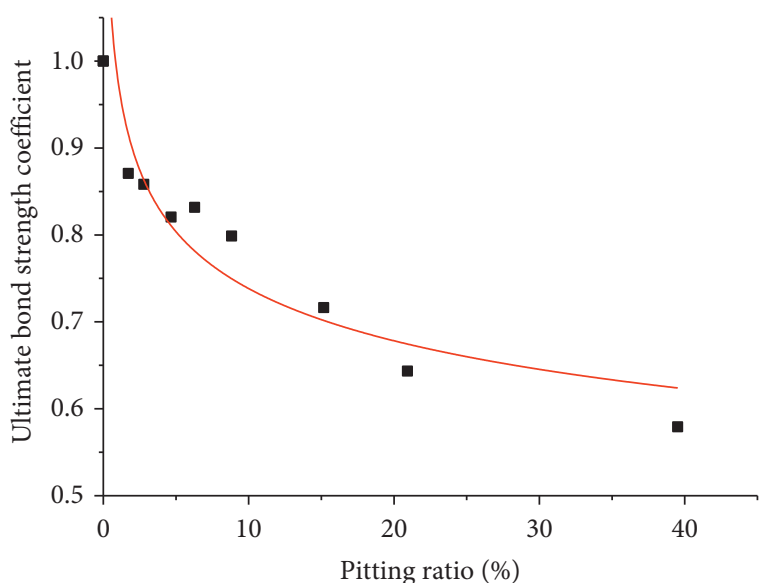

- Ultimate bond strength coefficient

Fitting curve of $K$ value of $45^{\circ}$ fracture angle and pitting ratio

(b)

FIGURE 14: Fitting curve of pitting corrosion degree and ultimate bond strength coefficient $K$.

and the weight of the reactant under ideal conditions, which will be disturbed by other factors in practice.

(2) The existence of joints and fissures in rock mass exposes anchor bars to seawater, so pitting corrosion of anchor bars is dominant in the initial stage. With the progress of corrosion, corrosion develops upward and downward along the pit, forming local corrosion.

(3) Since nonuniform corrosion (pitting) is the main form of corrosion, a formula for calculating pitting ratio by using the mass of overflow corrosion products is proposed in this paper. However, considering that the rust products produced by pitting corrosion cannot be overflowed in the actual situation, there are still some deviations in the actual calculation.

(4) In the local corrosion, the corrosion is more serious along the upward position of the pit. Before pitting corrosion ratio reaches $5 \%$, the migration distance increases rapidly and corrosion develops rapidly. Later, with the increase of pitting corrosion ratio, the migration distance increases slowly, and then slows down slowly.

(5) Corrosion has a significant effect on anchorage performance of anchor bars, and different pitting ratios have different effects on ultimate bond strength: when the pitting ratio is higher (9\%-30\%), the decline rate of maximum bond strength is significantly lower than that of the maximum bond strength under small pitting ratio $(1.5 \%-5 \%)$.

\section{Data Availability}

The data used to support the findings of this study are available from the corresponding author upon request.

\section{Conflicts of Interest}

The authors declare that they have no conflicts of interest.

\section{Acknowledgments}

The authors acknowledge the financial support provided by the National Natural Science Foundation of China (grant nos. 41572275), the Natural Science Foundation of Shandong Province (grant no. ZR2018MEE051), and the Project of Shandong Province Higher Educational Science and Technology Program (grant no. J15LG01).

\section{References}

[1] G. J. Al-Sulaimani, M. Kaleemullah, I. A. Basunbul, and Rasheeduzzafar, "Influence of corrosion and cracking on bond behavior and strength of reinforced concrete members," ACI Structural Journal, vol. 87, no. 2, pp. 220-231, 1990.

[2] J. G. Cabrera, "Deterioration of concrete due to reinforcement steel corrosion," Cement and Concrete Composites, vol. 18, no. 1, pp. 47-59, 1996.

[3] H.-S. Lee, F. Noguchi, and F. Tomosawa, "Evaluation of the bond properties between concrete and reinforcement as a function of the degree of reinforcement corrosion," Cement and Concrete Research, vol. 32, no. 8, pp. 1313-1318, 2002.

[4] K. Z. Hanjari, K. Lundgren, M. Plos, and D. Coronelli, "Three dimensional modelling of structural effects of corroding steel reinforcement in concrete," Structure and Infrastructure Engineering, vol. 9, no. 7, pp. 702-718, 2013.

[5] H. Karolina, V. Šmilauer, L. Jendele, and J. Červenka, "Prediction of reinforcement corrosion due to chloride ingress and its effects on serviceability," Engineering Structures, vol. 174, pp. 768-777, 2018.

[6] L. Chung, J.-H. Jay Kim, and S.-T. Yi, "Bond strength prediction for reinforced concrete members with highly corroded reinforcing bars," Cement and Concrete Composites, vol. 30, no. 7, pp. 603-611, 2008. 
[7] C.-Y. Gong, X.-Y. He, Y.-W. Li et al., "Long-term field corrosion monitoring in supporting structures of China Xiamen Xiangan Subsea Tunnel," Acta Metallurgica Sinica (English Letters), vol. 30, no. 4, pp. 399-408, 2017.

[8] C. A. Apostolopoulos and V. G. Papadakis, "Consequences of steel corrosion on the ductility properties of reinforcement bar," Construction and Building Materials, vol. 22, no. 12, pp. 2316-2324, 2008.

[9] R. Bayuaji, M. S. Darmawan, N. Husin, R. Anugraha, A. Budipriyanto, and M. Stewart, "Corrosion damage assessment of a reinforced concrete canal structure of power plant after 20 years of exposure in a marine environment: a case study," Engineering Failure Analysis, vol. 84, pp. 287-299, 2018.

[10] Y. Wu, H. Lv, S. Zhou, and Z. Fang, "Degradation model of bond performance between deteriorated concrete and corroded deformed steel bars," Construction and Building $\mathrm{Ma}$ terials, vol. 119, pp. 89-95, 2016.

[11] Y. Auyeung, P. Balaguru, and L. Chung, "Bond behavior of corroded reinforcement bars," ACI Materials Journal, vol. 97, no. 2, pp. 214-220, 2000.

[12] D. W. Law and T. C. Molyneaux, "Impact of corrosion on bond in uncracked concrete with confined and unconfined rebar," Construction and Building Materials, vol. 155, pp. 550-559, 2017.

[13] G. Grasselli, "3D Behaviour of bolted rock joints: experimental and numerical study: experimental and numerical study," International Journal of Rock Mechanics and Mining Sciences, vol. 42, no. 1, pp. 13-24, 2005.

[14] F. Li, Z. Liu, Y. Zhao, Y. Qu, and R. Lu, "Experimental study on corrosion progress of interior bond section of anchor cables under chloride attack," Construction and Building Materials, vol. 71, pp. 344-353, 2014.

[15] E. Gamboa and A. Atrens, "Material influence on the stress corrosion cracking of rock bolts," Engineering Failure Analysis, vol. 12, no. 2, pp. 201-235, 2005.

[16] E. Gamboa and A. Atrens, "Environmental influence on the stress corrosion cracking of rock bolts," Engineering Failure Analysis, vol. 10, no. 5, pp. 521-558, 2003.

[17] K. Spang and P. Egger, "Action of fully-grouted bolts in jointed rock and factors of influence," Rock Mechanics and Rock Engineering, vol. 23, no. 3, pp. 201-229, 1990.

[18] W. T. Ding and S. C. Li, "Effect of corrosion on reinforcement performance of anchorage support structure of subsea tunnel," Journal of South China University of Technology (Natural Science Edition), vol. 41, no. 6, pp. 100-107+139, 2013.

[19] S. Wu, H. Chen, H. L. Ramandi et al., "Investigation of cable bolts for stress corrosion cracking failure," Construction and Building Materials, vol. 187, pp. 1224-1231, 2018.

[20] H. Xu, Y. X. Zhang, and G. L. Wang, "Analysis of corrosion cracking model of anchorage body in consideration of rock actions," Rock and Soil Mechanics, vol. 31, pp. 1193-1198, 2010.

[21] R. C. Hassell, Corrosion of Rock Reinforcement in Underground Excavations, Western Australian School of Mines, Kalgoorlie, WA, Australia, 2008.

[22] J. T. Wen, W. S. Zhu, and S. C. Li, "Research on anchoring and shearing effect of anchoring cable," Chinese Journal of Rock Mechanics and Engineering, vol. 22, no. 10, pp. 1699-1703, 2003.

[23] S. C. Li, G. Wang, S. G. Wang, W. M. Yang, and X. G. Wang, "Application of fracture-damage model to anchorage of discontinuous jointed rockmass of excavation and supporting," Chinese Journal of Rock Mechanics and Engineering, vol. 25, no. 8, pp. 1582-1590, 2006.

[24] C. Fang, K. Lundgren, L. Chen, and C. Zhu, "Corrosion influence on bond in reinforced concrete," Cement and Concrete Research, vol. 34, no. 11, pp. 2159-2167, 2004.

[25] F. Tondolo, "Bond behaviour with reinforcement corrosion," Construction and Building Materials, vol. 93, pp. 926-932, 2015.

[26] J. Z. Xiao and B. Lei, "Experimental study on bond behavior between corroded steel bars and recycled concrete," Journal of Building Structures, vol. 32, no. 1, pp. 58-62, 2011.

[27] Q. Wu, Y. S. Yuan, J.-H. Jiang, and J. Zhu, "Experimental research on the bonding between corroded reinforcement bar and concrete," Journal of China University of Mining \& Technology, vol. 38, no. 5, pp. 685-691, 2009. 


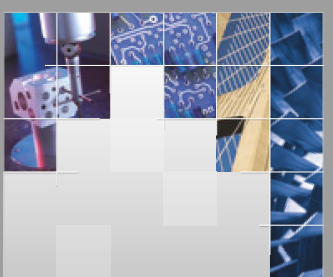

\section{Enfincering}
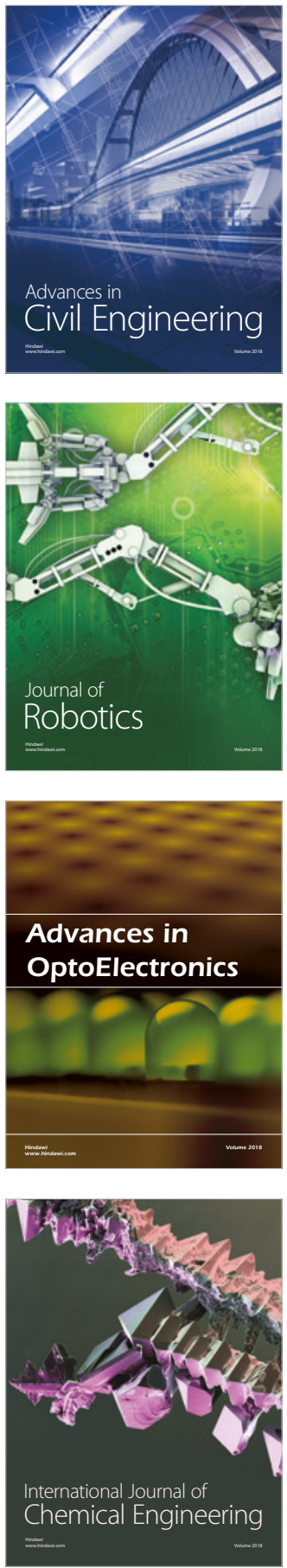

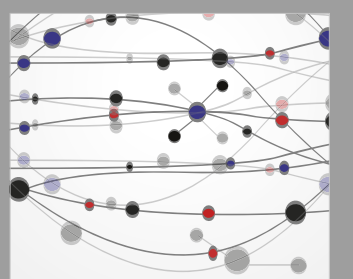

\section{Rotating \\ Machinery}

The Scientific World Journal

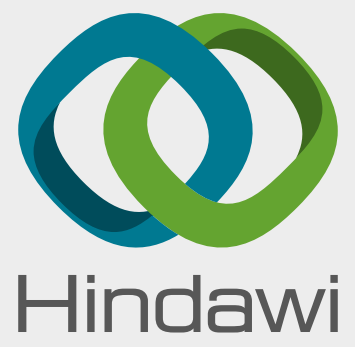

Submit your manuscripts at

www.hindawi.com
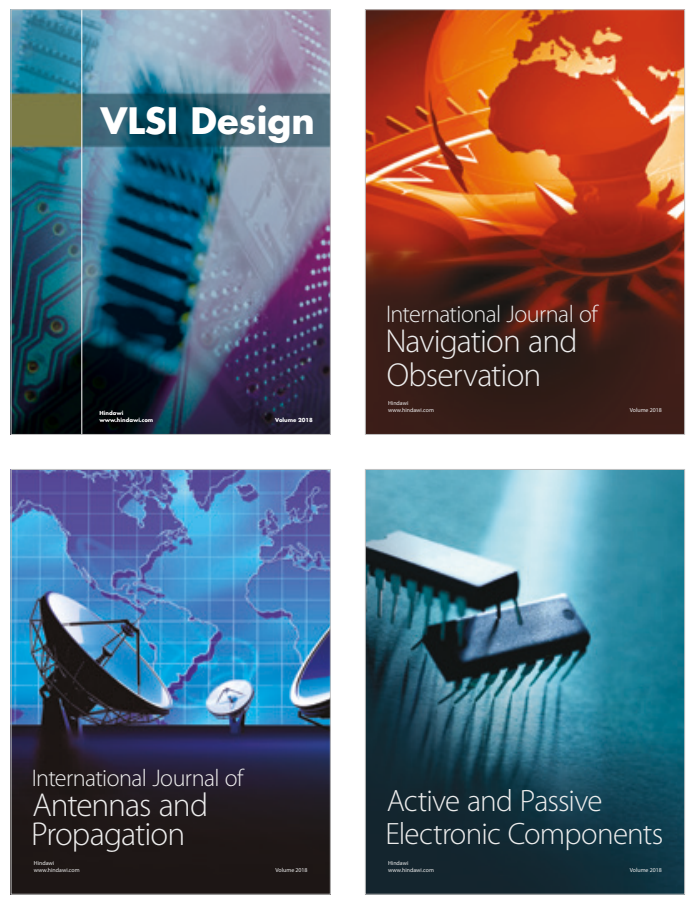
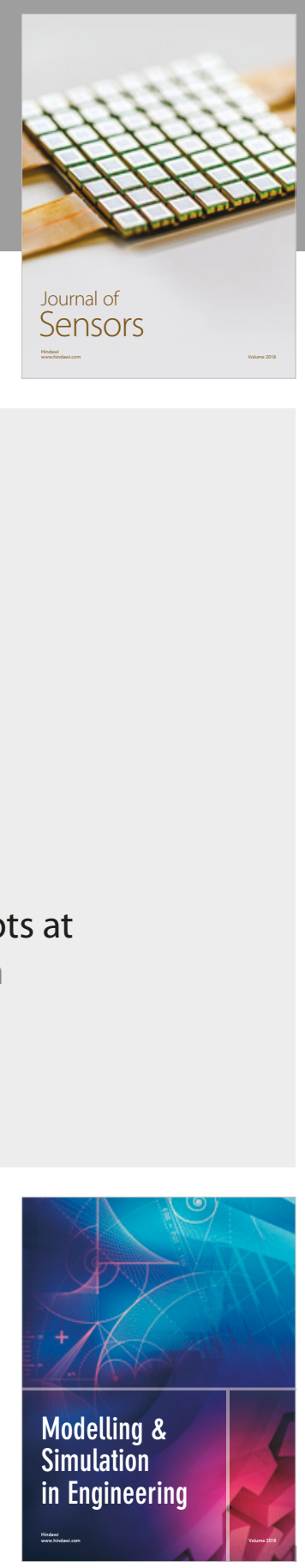

\section{Advances \\ Multimedia}
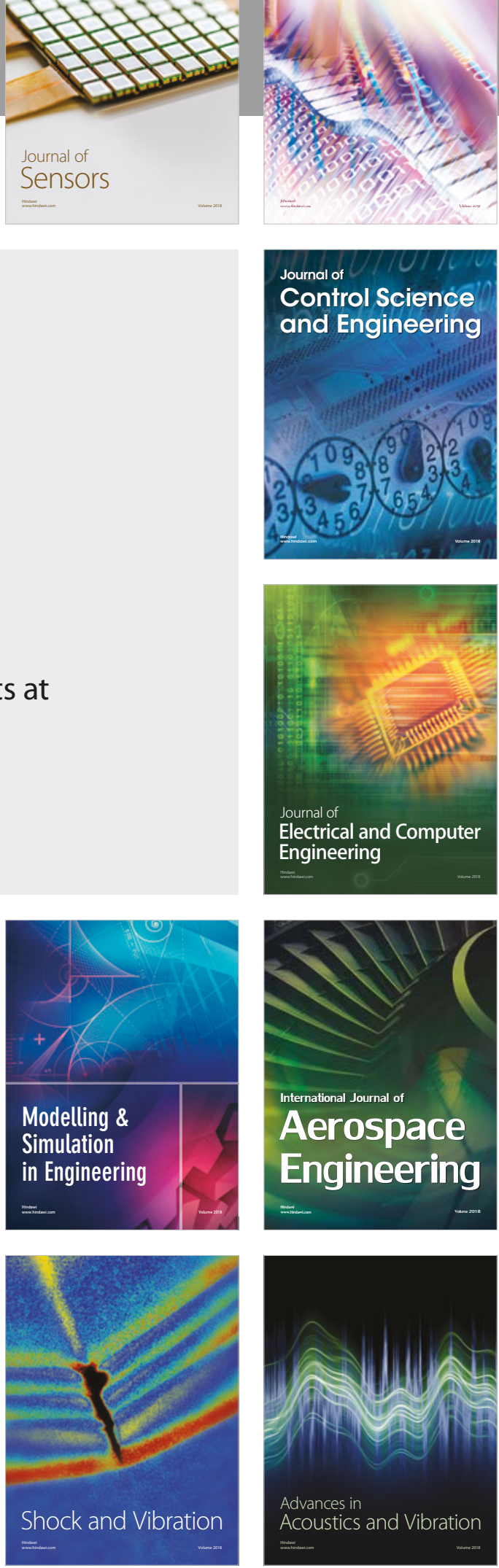